\title{
音

OS GRANDES PROJETOS E OS ESPAÇOS DE RESISTÊNCIA NA AMAZÔNIA: as comunidades em áreas de influência direta das estações portuárias em Rurópolis-PA

\section{DEVELOPMENT PROJECTS AND RESISTANCE SPACES IN THE}

AMAZON: communities in areas of direct influence of port seasons in Rurópolis, state of Pará, Brazil

\section{LOS GRANDES PROYECTOS Y LOS ESPACIOS DE RESISTENCIA EN LA AMAZONIA: las comunidades en áreas de influencia directa de las estaciones portuarias en Rurópolis, estado dePará, Brasil}

\begin{abstract}
Débora Aquino Nunes
Mestra em Planejamento do Desenvolvimento pelo Núcleo de Altos Estudos da Amazônia da Universidade Federal do Pará - NAEA/UFPA. Professora do Instituto Federal de Educação, Ciência e Tecnologia do Pará - IFPA/Campus Parauapebas. debora.aquino@ifpa.edu.br / http://orcid.org/0000-0002-5973-1962
\end{abstract}

\section{Gesiane Oliveira Trindade}

Mestra em Planejamento do Desenvolvimentó pelo Núcleo de Altos Estudos da Amazônia NAEA/UFPA. Professora do Instituto Federal de Educação, Ciência e Tecnologia do Maranhão IFMA/Campus Açailândia.

geisiane.oliveira@ifma.edu.br / http:/ /orcid.org/0000-0002-0453-4451

David Durval Jesus Vieira

Mestre em História Social da Amazônia pela Universidade Federal do Pará - UFPA. Professor do Instituto Federal de Educação, Ciência e-Tecnologia do Pará - IFPA/Campus Parauapebas. david.vieira@ifpa.edu.br /http://orcid.org/0000-0002-9364-1960

Recebido: 18/06/2019; Aceito: 21/09/2020; Publicado: 29/03/2021.

\section{RESUMO}

O presente trabalho tem como objetivo analisar a produção do espaço de comunidades diretamente afetadas por projetos de transporte de cargas na Amazônia oriental, tendo como recorte empírico as quatro comunidades (Santarenzinho, Livramento, Nazaré e Lago do Roque) da área de influência direta de três projetos de Estações de Transbordo de Cargas (ETC), que são denominados de ETC Rurópolis, ETC Tapajós e ETC Santarenzinho, localizados no município de Rurópolis, oeste paraense. Para realização dessa pesquisa, utilizou-se levantamento bibliográfico e documental sobre temas relacionados a esse estudo, bem como trabalho de campo com levantamento fotográfico, realização de entrevistas semiestruturadas e observação sistemática da paisagem. Entende-se que em parte da orla fluvial do município de Rurópolis coexistem as novas tendências de dominação econômica com as vivências ribeirinhas e agroextrativistas. Tal coexistência, entretanto, é, em grande parte, negligenciada pelas ações do poder público que se voltam para o reordenamento da região em prol do avanço do capital nacional e internacional em detrimento da (sobre)vivência de comunidades tradicionais. Destaca-se que em virtude da implantação desses projetos e dos interesses econômicos, do desrespeito à identidade e cultura desses povos, pelo poder público e privado, e da falta de proteção aos seus conhecimentos e territórios, a sobrevivência das comunidades pesquisadas passou a ser ameaçada. 
| Os grandes projetos e os espaços de resistência na Amazônia: as comunidades em áreas de influência direta das estações portuárias em Rurópolis-PA|

\title{
| Débora Aquino Nunes | Gesiane Oliveira Trindade | David Durval Jesus Vieira |
}

Palavras-chave: Comunidades Ribeirinhas e Agroextrativistas; Espaço de Resistência; Amazônia; Grandes Projetos.

\begin{abstract}
This article aims to analyze the production of the space of communities directly affected by cargo transportation projects in the Eastern Amazon. This study was conducted in four communities located in the area of direct influence of three projects of Transhipment Stations of Cargo (ETC). These ETC's are denominate ETC Rurópolis, ETC Tapajós and ETC Santarenzinho, and are located in Rurópolis, a municipality in the West of Pará. In this study were used: a) a bibliographic and documentary research; b) a fieldwork with photographic survey; c) semi-structured interviews; and d) a systematic observation of the landscape. It is understood that in part of the Rurópolis riverside, the new tendencies of economic domination coexist with the riverside and agro-extractive experiences. This coexistence is greatly neglected by the actions of the authorities. These actions goals are to reorder the region favoring the national and international capital advancement. However, it has been noticed some side effects in the traditional communities. It should be acknowledged that the survival of the researched communities is threatened due to the implementation of these projects and the economic interests in the region because there is a great disrespect to the identity and culture of these peoples by the public and private power. This directly affects the knowledge and territory of communities.
\end{abstract}

Keywords: Riverine and Agroextractive Communities; Space of resistance; Amazônia; Big Projects

\section{RESUMEN}

Este artículo tiene como objetivo analizar la producción del espacio de comunidades directamente afectadas por proyectos de transporte de carga en el este de la Amazonía. Nuestro estudio se realizó en cuatro comunidades ubicadas en el área de influencia directa de tres proyectos de Estaciones de Carga de Transbordo (ETC). Estos ETC se denominan ETC Rurópolis, ETC Tapajós y ETC Santarenzinho y están ubicados en el municipio de Ruropolis en el Paraense Oeste. En este estudio se utilizaron: a) investigación bibliográfica y documental; b) trabajo de campo con levantamiento fotográfico; c) entrevistas semiestructuradas; yd) observación sistemática del paisaje. Se entiende que en parte de la ribera del Rurópolis conviven las nuevas tendencias de dominación económica con las experiencias agro-extractivas y ribeira. Esta coexistencia se descuida en gran medida por las acciones de las autoridades. Estas están dirigidos al reordenamiento de la región a favor del avance del capital nacional e internacional en detrimento de las comunidades tradicionales. Cabe señalar que la supervivencia de las comunidades investigadas se vio amenazada debido a la implementación de estos proyectos y los intereses económicos en la región porque existe una gran falta de respeto a la identidad y la cultura de estos pueblos por parte del poder público y privado. Esto afecta directamente el conocimiento y el territorio de las comunidades.

Palabras clave: Comunidades Ribeirinhas y Agroextrativistas; Espacio de Resistencia; Amazon; Grandes Proyectos.

\section{INTRODUÇÃO}

A partir do governo militar, intensifica-se o processo de reestruturação espacial na Amazônia oriental. Esta aparece para o mundo como fronteira do capital, sendo cada vez mais incorporada por interesses econômicos e lógicas distantes. A fronteira é um espaço em incorporação ao capital global (BECKER, 1990) e também um lugar essencialmente da alteridade (MARTINS, 2009). 
| Os grandes projetos e os espaços de resistência na Amazônia: as comunidades em áreas de influência direta das estações portuárias em Rurópolis-PA|

|Débora Aquino Nunes | Gesiane Oliveira Trindade | David Durval Jesus Vieira |

Dessa forma, ela é, segundo os atores hegemônicos, o espaço de projeção para um futuro mais promissor, a nova fonte de recurso a ser explorada e onde se pode implantar rapidamente novas estruturas (BECKER, 1990). Além disso, ela é o lugar dos conflitos sociais, do (des)encontro de perspectivas que denotam tempos históricos distintos, ritmos de vida diferentes, formas de apropriação do espaço e do tempo que se misturam dialeticamente (MARTINS, 2009).

Nesse contexto, a importância do rio para a circulação e da floresta para a economia do extrativismo vegetal e para sobrevivência de inúmeros grupos sociais é, então, relativizada (CORREA, 1987). A terra também ganha um novo valor. Se antes o que predominava na região era o capital comercial, agora o capital especulativo, industrial e fundiário toma a frente dessa nova maneira de exploração regional (CORREA, 1987; DUTRA, 1997).

Assim, tanto as cidades como os espaços rurais vêm sofrendo transformações importantes. Rurópolis, por exemplo, município onde as comunidades pesquisadas se encontram, tem sua origem atrelada aos programas do governo militar para integração da Amazônia ao capital nacional e internacional, sob o slogan "Integrar para não entregar" (OLIVEIRA, 1987). Ressalta-se que os grandes projetos voltados principalmente para a exploração econômica da região, que ficaram famosos no regime militar, ainda não cessaram.

Atualmente, Rurópolis vem sofrendo com os atuais projetos pensados e implementados no Oeste Paraense, como: a) a instalação do porto da CARGILL em Santarém, município próximo - já que vários caminhoneiros usam a cidade de Rurópolis e entorno como ponto de parada e dormida, fomentando a prostituição, o tráfico de drogas e o desgaste das principais vias da cidade ${ }^{1}$; b) Instalação do porto de Miritituba, no município vizinho de Itaituba - tal projeto impacta também o município, principalmente a comunidade do quilômetro 30, por motivos parecidos com o da instalação do porto da Cargill; c) O asfaltamento das rodovias BR-163 e BR-230, como uma ação que modifica a vida na região, aumentando o tráfego de veículos, da população e da criminalidade, bem como de conflitos agrários (VENTURIERI et al., 2006); e d) atualmente, o projeto de instalação das Estações de Transbordo de Cargas (ETCs) - já gerou um especulação fundiária responsável por expulsar algumas famílias das comunidades, bem como conflitos internos nesses espaços, e possivelmente, caso esses projetos sejam instalados, modificarão ainda mais a relação das comunidades com o rio, a floresta e a terra.

\footnotetext{
${ }^{1}$ Informações cedidas por autoridades do município, como: o prefeito, o delegado e o representante da
} secretaria de assistência social. 
| Os grandes projetos e os espaços de resistência na Amazônia: as comunidades em áreas de influência direta das estações portuárias em Rurópolis-PA|

| Débora Aquino Nunes | Gesiane Oliveira Trindade | David Durval Jesus Vieira |

Destacamos também que a delimitação das Áreas de Influência, prevista na Resolução CONAMA 01/86 (CONAMA/IBAMA, 1986), é um dos requisitos legais para avaliação de impactos socioambientais, constituindo-se em fator de grande importância para o direcionamento da coleta de dados e obtenção do diagnóstico ambiental.

Neste artigo, foi considerada a Área de Influência Direta (AID) das ETCs em Rurópolis para o meio socioeconômico, os espaços delimitados pelos Relatórios de Impacto sobre o Meio Ambiente (RIMA’s) (AMBIENTARE, 2014a, 2014b e 2014c) e também identificados na pesquisa de campo desse trabalho. Estas são áreas potencialmente sujeitas aos impactos diretos da implantação e operação do empreendimento (IBAMA, 1986).

Nesse sentido, o presente trabalho tem como objetivo analisar a produção do espaço de comunidades diretamente afetadas por projetos de transporte de cargas na Amazônia oriental, tendo como recorte empírico as quatro comunidades (Santarenzinho, Livramento, Nazaré e Lago do Roque) da AID de três projetos de ETC, que são denominados de ETC Rurópolis, ETC Tapajós e ETC Santarenzinho, localizados no município de Rurópolis, oeste paraense.

Para realização dessa pesquisa, utilizaram-se como técnicas: o levantamento bibliográfico e também documental sobre temas relativos à pesquisa, bem como trabalho de campo com levantamento fotográfico (SAMAIN, 1995), realização de entrevistas semiestruturadas (FRASER; GODIM, 2004) e observação sistemática da paisagem, com o uso de caderno de campo (MAGNANI, 2002).

Desvelamos, então, contradições e especificidades no processo de produção do espaço de parte da orla fluvial de Rurópolis que podem estimular outras proposições de políticas de desenvolvimento regional que respeitem as diferenças e a (re)produção da vida dos grupos sociais ligados à terra, ao rio e/ou à floresta, na Amazônia oriental.

\section{A MODERNIZAÇÃo DA AMAZÔNIA E O MUNICÍPIO DE RURÓPOLIS:} mudanças e permanências no viver, perceber e conceber o espaço

Segundo Lefebvre (2008a, 2008b), o espaço é produto social, admitindo diversas estratégias de grupos desiguais e diferentes, sendo um "médium", meio e mediação, instrumento e intermediário, dos diversos grupos sociais. Ele é percebido-vivido-concebido (LEFEBVRE, 1974) e carrega consigo as marcas de diferentes processos e contextos histórico-geográficos, assim como desenha novas possibilidades a partir das potencialidades do presente (LEFEBVRE, 2008b). 
| Os grandes projetos e os espaços de resistência na Amazônia: as comunidades em áreas de influência direta das estações portuárias em Rurópolis-PA|

| Débora Aquino Nunes | Gesiane Oliveira Trindade | David Durval Jesus Vieira |

O espaço pode ser entendido e analisado a partir da trialética entre percebidovivido-concebido. O percebido ou práticas espaciais está ligado à base prática de percepção do mundo, principalmente aquelas que refletem o modo de produção vigente, na sociedade contemporânea, o capitalismo. Ele se relaciona aos conjuntos espaciais e lugares específicos de cada formação espacial, que assegura a continuidade do modo de produção numa relativa coesão e sequência. Nele, a reprodução das relações sociais estabelecidas predomina.

O vivido ou espaços de representação, por sua vez, é encharcado de simbolismos, de arte, de criação e de clandestinidade, onde se desenvolve a vida cotidiana, as virtualidades e as possibilidades que jamais se sujeitam à "coerência" e à homogeneização. Ele está ligado aos espaços dos habitantes, dos "usadores", que é vivido sob os termos da apropriação; são os lugares da paixão, da ação e da imaginação.

O concebido ou representação do espaço liga-se às relações de produção, à ordem que elas "impõem”, aos seus signos, aos seus conhecimentos e aos seus códigos. Ele é a representação mental, o produto do saber (conhecimento e ideologias misturadas) e da razão, e por isso pertencente aos planificadores, urbanistas e tecnocratas (LEFEBVRE, 1974), ou seja, aqueles agentes que projetam, muitas vezes de forma autoritária e reducionista, intervenções, planos e programas para o espaço social.

Não designando um produto qualquer, coisa ou objeto, mas um conjunto de relações sociais, o espaço não pode ser concebido como vazio, estático, passivo ou como apenas objeto de troca. Por interação ou retroação, o espaço intervém na própria produção social, sendo condição, produto e produzido pelos grupos sociais (LEFEBVRE, 1974).

A produção do espaço na Amazônia passou por diversos momentos históricosgeográficos-culturais de resistências e exploração. Antes do processo de colonização europeia, o espaço amazônico estava organizado para garantir formas simples de sobrevivência dos seus grupos sociais. Isso não significa dizer que as relações sociais, antes predominantes, fossem harmônicas ou estivessem isentas de conflitos, e sim que estavam orientadas pela dimensão do uso, sendo, até mesmo, as trocas baseadas na utilidade dos objetos (OLIVEIRA, 2000).

$\mathrm{Na}$ Amazônia essa dinâmica começou a ser transformada a partir do século XVII com a entrada dos colonizadores, principalmente portugueses. Movidos principalmente por interesses políticos, de dominação do território, e econômicos, de exploração das drogas do sertão e da mão de obra local, eles adentraram na região (CORRÊA, 1987; CASTRO, 2008). 
| Os grandes projetos e os espaços de resistência na Amazônia: as comunidades em áreas de influência direta das estações portuárias em Rurópolis-PA|

|Débora Aquino Nunes | Gesiane Oliveira Trindade | David Durval Jesus Vieira |

Há, então, um choque com as relações de produção e com a produção das relações até então existentes; fundamentadas na interação mais direta entre os homens e deles com a natureza, provocando novos conflitos (OLIVEIRA, 2000).

Além disso, destacamos que o processo de colonização não conseguiu fomentar a criação de uma rede urbana sólida e o povoamento em modelo europeu na região. A urbanização da Amazônia começa a ganhar fôlego apenas a partir do final do século XIX, com a exploração do látex (MACHADO, 1999).

O látex (matéria-prima da borracha) foi a base econômica da região até a década de 1920, período que começou a se consolidar a chamada "crise da borracha", que assolou a Amazônia até a década de 1960, com exceção de algumas cidades que conseguiram substituir a sua produção extrativista voltada ao mercado internacional, como Santarém com a juta, e Marabá com a castanha-do-pará (VELHO, 1972; EMMI, 1999).

Na década de 1880, sementes e mudas de seringueiras, das quais era retirado o látex (goma elástica da borracha), foram distribuídos em partes da Ásia, que apresentava clima quente e úmido, semelhante à Amazônia. No período de 1911-1920, teve-se a produção racional da Ásia, que superou, em muito, a brasileira. Com a maior oferta de borracha no mercado internacional, seus preços diminuíram. Nesse contexto, verifica-se uma crise econômica, alimentar e social, bem como o aumento da dívida pública interna e externa

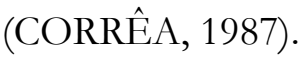

A região como um todo volta a ser alvo mais direto e intenso das investidas do capital, principalmente após 1960. Esse período foi marcado pelo acelerado crescimento do número de centros urbanos, na população ali assentada, nos valores e costumes urbanos que invadiram a região e nos seus objetos técnicos correspondentes (TRINDADE JR.; TAVARES, 2008). Difundem-se também as relações de trabalho formais e a produção capitalista se dispersa na floresta, no campo e na cidade (BECKER, 1990).

Nesse contexto, um programa que impactou diretamente Rurópolis foi o de Urbanismo Rural, comandado pelo Instituto Nacional de Colonização e Reforma Agrária (INCRA). Tal programa visava a ocupação da Amazônia através de um sistema de núcleos urbanos configurados em localidades centrais hierarquizadas. Os núcleos mais importantes eram denominados de Rurópolis, os núcleos secundários eram as Agropólis e, posteriormente, os terciários formaram as Agrovilas (BECKER, 1990).

Através dessa política federal orientada para a região, foram implantadas várias Agrovilas, apenas uma Agrópolis (a Brasil Novo, no Km 46 do trecho Altamira/Itaituba) e, finalmente, às proximidades do cruzamento da Transamazônica com a Rodovia Santarém - 
| Os grandes projetos e os espaços de resistência na Amazônia: as comunidades em áreas de influência direta das estações portuárias em Rurópolis-PA|

|Débora Aquino Nunes | Gesiane Oliveira Trindade | David Durval Jesus Vieira |

Cuiabá (atual BR-163), foi construída uma Rurópolis - a Presidente Médici (CARDOSO, LIMA, 2009).

A atual sede do município de Rurópolis constitui-se exatamente nesse núcleo planejado e implantado para o qual continuam, nos anos seguintes, a chegar migrantes de outras partes do Brasil (CARDOSO; LIMA, 2009). A partir desse contexto, o Estado passa a ter uma força central na construção do espaço regional e do município.

Em Rurópolis, até os dias atuais, permanecem alguns colonos com os lotes de 100 ha distribuídos através do programa Urbanismo Rural. Esses colonos (re)existem em meio aos constantes ataques do capital que vem se intensificando na Amazônia nos últimos anos. Nesse sentido, identifica-se que historicamente solapam-se, em graus diversos e com intensidades variadas, as estruturas de produção tradicionais na Amazônia (CASTRO, 1999). Nas cidades e nas florestas, os usos se dissolvem e minguam as solidariedades ancestrais. O dinheiro passa, então, a tentar ser a medida de tudo, impondo à vida social uma competitividade e um selvagerismo crescentes (SANTOS, 2007). Tudo pode ser transformado em capital. Porém, algumas relações escapam e resistem a essa nova lógica. Em certas situações, até mesmo reforçam-se as relações tradicionais de trabalho e de reprodução da vida (CASTRO, 1999; MARTINS, 2009, 2011; LIMA, 2013), como as que têm na apropriação do espaço e na resistência da relação entre homem e rio-floresta-terra os fundamentos da sua (sobre)vivência. Apropriação essa que foi identificada e analisada nas comunidades diretamente impactadas pelo projeto de Estações de Transbordo de Carga em Rurópolis-PA.

\section{COEXISTENNCIAS CONTRADITÓRIAS ENTRE GRANDES PROJETOS E COMUNIDADES RIBEIRINHAS/AGROEXTRATIVISTAS EM RURÓPOLIS-}

\section{PA: a produção do espaço nas comunidades diretamente afetadas pelas ETCs}

A produção do espaço das comunidades ribeirinhas e agroextrativistas da Amazônia é complexa e comporta inúmeras temporalidades e espacialidades simultâneas. Destaca-se que podemos relacionar a construção dos portos com a necessidade de integração da região ao capital internacional e nacional, ou seja, a "economia". Há uma necessidade constante de aumento do fluxo de mercadorias no mundo e diminuição no seu tempo de giro (da produção ao consumo), pois esse é um dos pilares do capitalismo. Essencialmente mercadófilos, tais projetos desconsideram as práticas, os saberes, as necessidades e as vivências das comunidades atingidas. 
| Os grandes projetos e os espaços de resistência na Amazônia: as comunidades em áreas de influência direta das estações portuárias em Rurópolis-PA|

| Débora Aquino Nunes | Gesiane Oliveira Trindade | David Durval Jesus Vieira |

Os Estudos de Impacto Ambiental - EIA e os Relatórios de Impacto Ambiental RIMA das estações de transbordo de cargas ETC Rurópolis, ETC Santarenzinho e ETC Tapajós, respectivamente de responsabilidade das empresas Transportes Bertolini, Odebrecth TransPort e Companhia Norte de Navegação e Portos - CIANPORT, apresentam como objetivo das ETCs a "integração dos modais hidroviário e rodoviário na região" (AMBIENTARE, 2014a, p. 8), para facilitar o transporte de semirreboques, cargas gerais e safras agrícolas (AMBIENTARE, 2014a, 2014b e 2014c).

Destaca-se que a escolha da implantação dos projetos na comunidade de Santarenzinho, dentre outros fatores, deu-se em razão da sua localização estratégica, pois permite uma melhor utilização integrada dos sistemas rodoviários (Transamazônica e BR163) e hidroviário (hidrovia Tapajós-Amazonas) brasileiro (AMBIENTARE, 2014a, 2014b e 2014c).

A produção agrícola, que será transportada e exportada, tem sua origem no estado do Mato Grosso e atualmente possui como destino outros portos do país. Assim, para o melhor e mais rápido escoamento, faz-se necessária a viabilização da conexão dos modais rodoviários e hidroviários em Rurópolis. A instalação de toda essa infraestrutura será capaz de movimentar 4.000.000 toneladas/ano de grãos (soja e milho), 3.850 .000 t/ano de fertilizantes e 100.000 contêineres/ano (AMBIENTARE, 2014a, 2014b e 2014c).

Segundo dados constantes nos RIMA's, com a consolidação da BR-163 (CuiabáSantarém), o trecho rodoviário para o escoamento da produção de grãos, por exemplo, passará a ser em média $1.100 \mathrm{~km}$ até Rurópolis (PA). Assim, deixa-se de percorrer até 2.300 km por modal rodoviário até os portos de Paranaguá (PR) ou Santos (SP). Essas estações também reforçam o conceito de multimodalidade, podendo se integrar com o terminal hidroviário de Santarém na região do oeste paraense. Expandem-se as condições de exportação brasileira por hidrovias (AMBIENTARE, 2014a, 2014b e 2014c).

Ainda segundo os RIMA's, está estimada uma movimentação de 1.214 caminhões por dia, na fase de operação do complexo, o que possivelmente trará uma enorme transformação na região e nas comunidades pesquisadas. Ademais, serão ofertados 930 empregos diretos durante a fase de instalação e 377 na fase de operação dos empreendimentos (AMBIENTARE, 2014a, 2014b e 2014c). Nesse sentido, além da demissão em massa entre essas fases, é previsto um aumento na migração para essa região que ultrapassa os postos de trabalho ofertados (AMBIENTARE, 2014a).

Destaca-se que todas as ETC's previstas para Rurópolis estão em fase de planejamento e licenciamento, com exceção da ETC Rurópolis, da empresa Bertolini, que possui licença de instalação desde 2017. Porém, para esta empresa começar a operar, o 
|Os grandes projetos e os espaços de resistência na Amazônia: as comunidades em áreas de influência direta das estações portuárias em Rurópolis-PA|

| Débora Aquino Nunes | Gesiane Oliveira Trindade | David Durval Jesus Vieira |

COEMA solicitou que ela cumpra exigências na área de saúde e medidas para garantir a regularidade do empreendimento. Já o Ministério Público apresentou uma avaliação técnica sobre o Estudo de Impacto Ambiental (EIA) feito pela empresa e solicitou uma análise mais detalhada das questões que envolvem os impactos sociais e no meio ambiente. A partir dessas novas pesquisas e cumprimento de exigências é que a licença de operação poderá ser expedida para Bertolini (SEMAS, 2017). Em 2019, as empresas por trás das ETC's entraram em contato com o governo do Estado do Pará no intuito de viabilizar o complexo portuário de Santarenzinho. Para isso, o governo ficou responsável de construir uma estrada de acesso ao local onde está planejada a instalação dos portos (SERIQUE, 2019). Até o atual momento, esse complexo portuário não está em funcionamento, porém os terrenos já foram adquiridos pelas empresas e os processos de licenciamento estão em andamento, bem como o aprofundamento dos contatos entre as grandes empresas e as instituições ligadas ao governo de Estado.

Já é sabido que esses grandes projetos trazem consigo violências de todo tipo, conflitos agrários, aumento do tráfico de drogas e atropelamentos. Além disso, os empregos que são destinados às comunidades da área de influência direta são aqueles que exigem baixa escolaridade e remuneração. Todas essas questões foram apontadas como saberes e preocupações constantes dos entrevistados/comunitários.

Assim, as comunidades aqui pesquisadas se encontram em meio a coexistência de mudanças e permanências, que vem se aprofundando nos últimos anos na região. Historicamente, conforme exposto pelos líderes comunitários e famílias entrevistadas, as práticas ribeirinhas e agroflorestais sempre tiveram influência direta na (re)produção de suas vidas e na produção de seu espaço. O espaço vivido desses grupos se apresenta extremamente conectado com os cursos fluviais, a floresta e a terra. Tal espaço, para efeitos da presente análise, é considerado como realidades sociogeográficas onde se manifestam fortes relações de permanência da interação multidimensional entre os grupos sociais e deste com o meio em que vivem, configurando-se como uma das expressões sociais multifacetadas na Amazônia, que merece ser entendida e, igualmente, considerada pelas políticas regionais.

A produção do espaço nessas comunidades também está permeada pela lógica hegemônica do capital. A venda da força de trabalho se realiza principalmente em relação ao emprego temporário nas pequenas e médias mineradoras localizadas às margens do rio Tapajós em Santarenzinho. Em todas as comunidades foram identificados trabalhadores ou extrabalhadores dessas empresas. Destaca-se, segundo os entrevistados, que normalmente o trabalhador fica no emprego em média 3 meses. Isso porque esse era o tempo máximo do 
|Os grandes projetos e os espaços de resistência na Amazônia: as comunidades em áreas de influência direta das estações portuárias em Rurópolis-PA|

\section{| Débora Aquino Nunes | Gesiane Oliveira Trindade | David Durval Jesus Vieira |}

período de experiência do trabalhador - após isso a empresa deve assinar a sua carteira de trabalho e pagar os seus direitos trabalhistas, o que aumenta os custos e diminui o lucro.

A mão de obra é subempregada também nas grandes propriedades. É comum o trabalho temporário na produção e manutenção dos grandes lotes de terra. Outras importantes fontes de renda identificadas são também a aposentadoria e o Bolsa Família - programa do governo federal que busca diminuir a desigualdade social através da distribuição de uma certa renda para populações de baixa renda. Todas as famílias visitadas ou entrevistadas possuíam acesso a pelo menos uma televisão, um cartão de banco e um celular.

Nesse contexto, as comunidades pesquisadas são elos entre o posto e o imposto, o alternativo e o impossível. As principais características das comunidades ribeirinhas diretamente atingidas pelos projetos de ETCs são apresentadas no quadro 01.

Quadro 01 - Principais características das comunidades ribeirinhas na Área de Influência Direta das Estações de Transbordo e Carga em Rurópolis-PA

\begin{tabular}{|c|c|c|c|}
\hline & Localização & Principais elementos da paisagem & Principais usos e atividades \\
\hline $\begin{array}{l}\text { Santa- } \\
\text { renzinho }\end{array}$ & $\begin{array}{l}\text { Rio } \\
\text { Tapajós }\end{array}$ & $\begin{array}{l}\text { Casas de madeira e mistas }{ }^{1} \text {; tábuas de } \\
\text { madeira dentro do rio para lavagem } \\
\text { de roupas/louças; embarcações } \\
\text { (canoas, rabetas, balsas, voadeiras e } \\
\text { "popopo"2); pequenos e médios } \\
\text { animais (galinha, porco, pato e gado); } \\
\text { roças; casa de farinha; cadeiras em } \\
\text { frente das casas; redes de pesca } \\
\text { dentro do rio e/ou sendo tecidas e } \\
\text { consertadas em frente das casas; } \\
\text { empresas de mineração (Cominas e } \\
\text { Calreis); Área Comunitária; porto de } \\
\text { embarque para gado; Pousada } \\
\text { Tapajós; e vestígios arqueológicos; }\end{array}$ & $\begin{array}{l}\text { Moradia; movimentação de } \\
\text { canoas, rabetas, balsas, voadeiras } \\
\text { e "popopo"2; atividade pesqueira } \\
\text { e de agricultura familiar; criação } \\
\text { de pequenos e médios animais; } \\
\text { lazer no rio e na ribeira; uso } \\
\text { doméstico da ribeira e da água do } \\
\text { rio; atividade de esporte e lazer } \\
\text { no campo de futebol e na sede do } \\
\text { clube; atividade religiosa; } \\
\text { atividade industrial; e atividade } \\
\text { turística; produção de farinha. }\end{array}$ \\
\hline Livramento & $\begin{array}{l}\text { Lago do } \\
\text { Livra-mento }\end{array}$ & $\begin{array}{l}\text { Casas de madeira e mistas }{ }^{1} \text {; tábuas de } \\
\text { madeira dentro do rio para lavagem } \\
\text { de roupas/louças; de pequenos e } \\
\text { médios animais (galinha, porco, pato } \\
\text { e gado); casa de farinha; embarcações } \\
\text { (canoas, rabetas e "popopo"2); } \\
\text { cadeiras em frente das casas; redes de } \\
\text { pesca dentro do Lago e/ou sendo } \\
\text { tecidas e consertadas em frente das } \\
\text { casas; Área comunitária. }\end{array}$ & $\begin{array}{l}\text { Moradia; movimentação de } \\
\text { canoas, rabetas e "popopo"2; } \\
\text { atividade pesqueira e de } \\
\text { agricultura familiar; criação de } \\
\text { pequenos e médios animais; lazer } \\
\text { no rio e na ribeira e uso } \\
\text { doméstico da ribeira e da água do } \\
\text { rio; produção de farinha. }\end{array}$ \\
\hline Nazaré & Lago Nazaré & $\begin{array}{l}\text { Casas de taipa, madeira e mistas }{ }^{1} \text {; } \\
\text { tábuas de madeira dentro do rio para } \\
\text { lavagem de roupas/louças; } \\
\text { embarcações (canoas, rabetas e } \\
\text { "popopo"2); pequenos e médios } \\
\text { animais (galinha, porco, pato e gado); } \\
\text { cadeiras em frente das casas; redes de } \\
\text { pesca dentro do rio e/ou sendo } \\
\text { tecidas e consertadas em frente das } \\
\text { casas; Área comunitária; Escola } \\
\text { Municipal de Ensino Fundamental } \\
\text { Nazaré II; taberna; roças; casa de } \\
\text { farinha; e vestígios arqueológicos; }\end{array}$ & $\begin{array}{l}\text { Moradia; movimentação de } \\
\text { canoas, rabetas e "popopo"2; } \\
\text { atividade pesqueira e de } \\
\text { agricultura familiar; criação de } \\
\text { pequenos e médios animais; } \\
\text { comércio (taberna); produção de } \\
\text { farinha; lazer no rio e na ribeira; } \\
\text { uso doméstico da ribeira e da } \\
\text { água do rio; atividade de esporte } \\
\text { e lazer no campo de futebol e na } \\
\text { sede do clube; e atividade } \\
\text { religiosa. }\end{array}$ \\
\hline
\end{tabular}


|Os grandes projetos e os espaços de resistência na Amazônia: as comunidades em áreas de influência direta das estações portuárias em Rurópolis-PA|

\section{| Débora Aquino Nunes | Gesiane Oliveira Trindade | David Durval Jesus Vieira |}

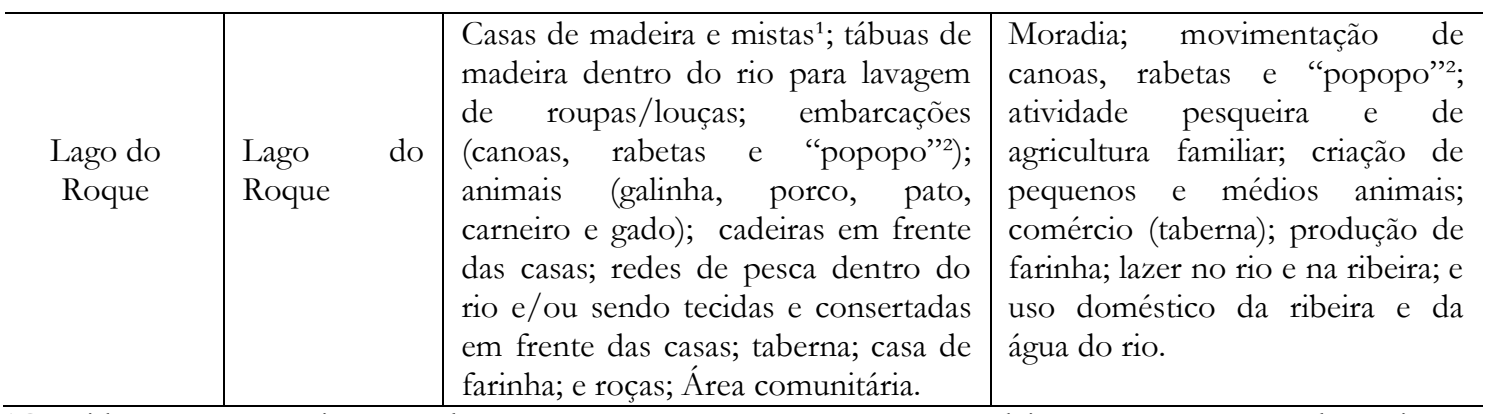

${ }^{1}$ Consideramos casas mistas aquelas que são compostas uma parte por madeira e outra parte por alvenaria.

2 O tipo de embarcação denominada "popopo" é típica da região amazônica e muito utilizada para transporte de passageiros entre diferentes localidades.

Fonte: Trabalho de campo, 2015. Elaboração: Débora Aquino Nunes.

Identificamos que as principais formas-conteúdos das comunidades pesquisadas nos remetem a práticas ligadas ao rio e ao agroextrativismo. Assim, ao chegarmos às comunidades logo reconhecemos tais formas-conteúdos e vivências ligadas às águas, à pequena agricultura e à criação de animais (Fig. 01 e 02).

Figura 01 - Práticas e usos do rio e da ribeira na comunidade de Santarenzinho: existência da atividade pesqueira, o uso doméstico da água do rio e a criação

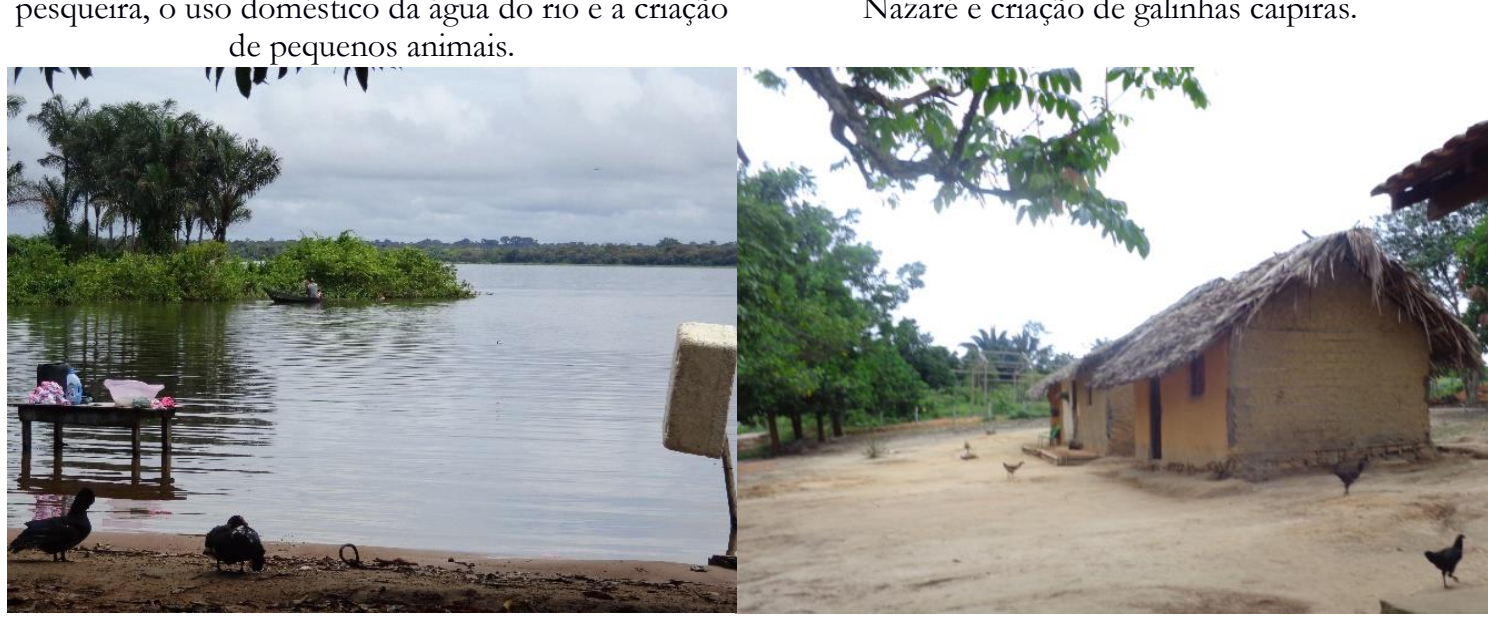

Autora: Débora Aquino Nunes, 2015.
Figura 02 - Casas de taipa na comunidade de Nazaré e criação de galinhas caipiras.

As formas não existem por si só, mas são dotadas de conteúdo, de significado através da ação humana. As formas e os conteúdos se influenciam mutuamente. Assim, os lugares se criam e se recriam novamente. Pode-se dizer que a forma, em qualidade de forma-conteúdo, está sendo permanentemente alterada e que o conteúdo ganha novo significado ao encaixar-se na forma. A ação social se relaciona diretamente com a forma que a contém. Nesse sentido, os processos apenas ganham inteira significação quando corporificados (SANTOS, 2008).

Ademais, identificamos as principais atividades econômicas e de subsistência da população. Entendemos que os produtos agroflorestais ou agroextrativistas são oriundos 
|Os grandes projetos e os espaços de resistência na Amazônia: as comunidades em áreas de influência direta das estações portuárias em Rurópolis-PA|

| Débora Aquino Nunes | Gesiane Oliveira Trindade | David Durval Jesus Vieira |

de práticas homônimas que combinam extrativismo com agricultura e/ou com a criação animais numa mesma área. A presença de árvores e/ou arbustos no sistema produtivo pode trazer benefícios diretos e indiretos, tais como: o controle da erosão e manutenção da fertilidade do solo, o aumento da biodiversidade, a diversificação da produção e o alongamento do ciclo de manejo de uma área. O objetivo principal dessa atividade é de otimizar o uso da terra, conciliando a produção florestal com a produção de alimentos, conservando o solo e diminuindo a pressão pelo uso da terra para produção agrícola (ENGEL, 1999).

Nas comunidades pesquisadas, a produção e o comércio da farinha foram identificados. São produzidos de 6 a 10 sacos de farinha por semana, no período de safra, numa média de R \$120,00 o saco. Algumas casas de farinhas são utilizadas por mais de uma família (Fig. 03). Outras culturas agrícolas também são trabalhadas, como o feijão e o arroz. A renda média da população dessas comunidades gira em torno de um pouco mais ou um pouco menos de um salário mínimo/família por mês.

Figura 03 - Casa de Farinha em Santarenzinho: construção feita de madeira e palha que abriga o forno e

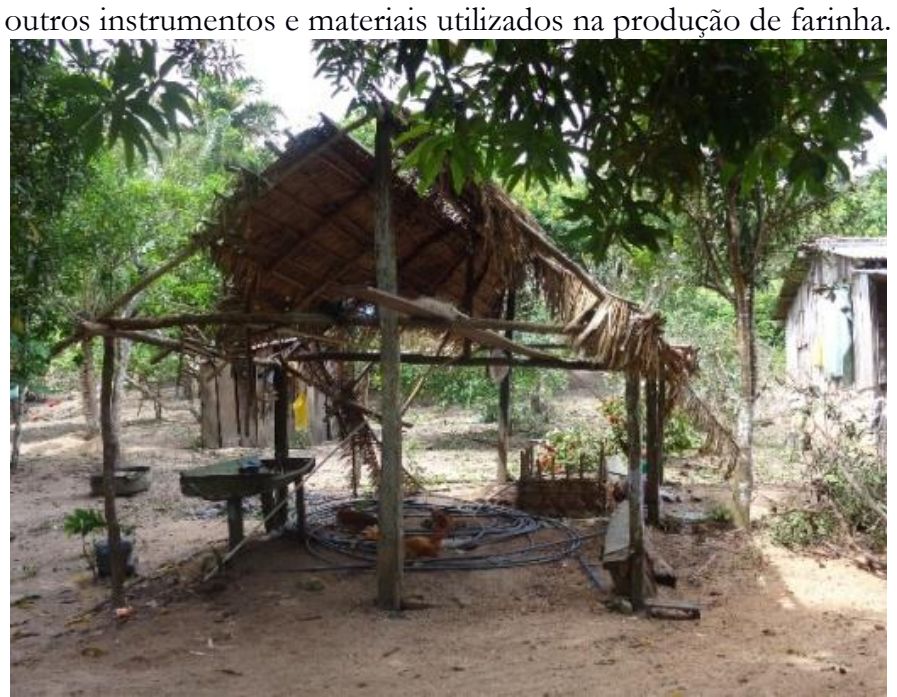

Autora: Débora Aquino Nunes, 2015.

Em relação à pesca, os principais peixes comercializados são: Aracu, Piau, Barbado, Dourada, Filhote, Jandiá, Jaraqui, Pescada Branca, Tucunaré, Pirarucu, Tilápia, Tambacú, variando de $\mathrm{R} \$ 2,00$ a $\mathrm{R} \$ 15,00$ o quilo, dependendo da espécie e período. Em relação aos instrumentos de trabalho da pesca, são utilizados espinhais, malhadeiras, tarrafas, linha e varas. A maioria dos peixes e também da produção são levados através do rio e comercializados na cidade de Itaituba ou nas frentes das casas dos pescadores.

As comunidades pesquisadas são caracterizadas por sua natureza diferencial de uso e apropriação do espaço em relação aos centros urbanos, onde a lógica do dinheiro e a 
| Os grandes projetos e os espaços de resistência na Amazônia: as comunidades em áreas de influência direta das estações portuárias em Rurópolis-PA|

|Débora Aquino Nunes | Gesiane Oliveira Trindade | David Durval Jesus Vieira|

velocidade crescente das relações e da vida predominam. Faz-se importante dizer que eles produzem e reproduzem o espaço amazônico de maneira particular e também singular, abrindo um leque de possibilidades e virtualidades, baseadas em necessidades vividas e percebidas, bem como nas intervenções concebidas pelas políticas públicas para região que se inscrevem e transformam os espaços. Situa-se o rio, a natureza e a terra como parte das dinâmicas que lhe são inerentes. Assim, muitas práticas assinaladas a partir desses espaços deixam registros de relações cotidianas carregadas de significados e sendo significantes na paisagem.

Os grupos sociais que produzem o espaço dessas comunidades não estão apenas à beira-rio ou em comunidades rurais, mas se situam e interagem com e a partir da terra, da floresta e também do rio e da ribeira ${ }^{2}$. Desenvolvem desde interações e manifestações de atividades econômicas, de mobilidade e de subsistência - como a pesca, as atividades agroextrativistas, o transporte, o uso doméstico da água do rio - até manifestações de natureza mais lúdica, de lazer, de entretenimento e de imaginário cultural, como os banhos de rio, os encontros e relações de vizinhança, as festas, as lendas e as histórias e estórias dos indivíduos e dos grupos.

O ritmo de suas vidas segue fortemente conectado com o meio. O peixe fresco na mesa, bem como frutas, farinha e galinhas caipiras fazem parte do cardápio da maioria das casas nas comunidades. Além da alimentação, essa forte relação com o meio também desenha significados diversos na vida dessa população. As lendas e mitos giram em torno das águas e da floresta. São de conhecimento comum as armadilhas do curupira, da cobra grande e de outras entidades que habitam a floresta.

Dando mais fôlego às lendas e mitos contados, é necessário frisar que as comunidades ficam próximas a um sítio arqueológico onde podem ser encontrados diversos tipos de materiais, desde pedras lascadas à cerâmica portuguesa e balas de revolver antigo. A comunidade de Santarenzinho, na verdade, localiza-se em cima de um sítio arqueológico (Fig. 04 e 05).

\footnotetext{
2 O termo "ribeira" se remete à faixa imediata de maior contato e interação entre a terra e a água. Ele designa espaços onde se desenvolvem usos e práticas socioespaciais cotidianas que estão ligados ao tempo lento do rio e da floresta, de forma múltipla (econômica, funcional e simbólico-cultural) (LIMA, 2013).
} 
|Os grandes projetos e os espaços de resistência na Amazônia: as comunidades em áreas de influência direta das estações portuárias em Rurópolis-PA|

| Débora Aquino Nunes | Gesiane Oliveira Trindade | David Durval Jesus Vieira |

Figura 04 - Museu Vovô Afonso - Santarenzinho. Figura 05 - Túmulo localizado na comunidade de Santarenzinho, com datação não definida.

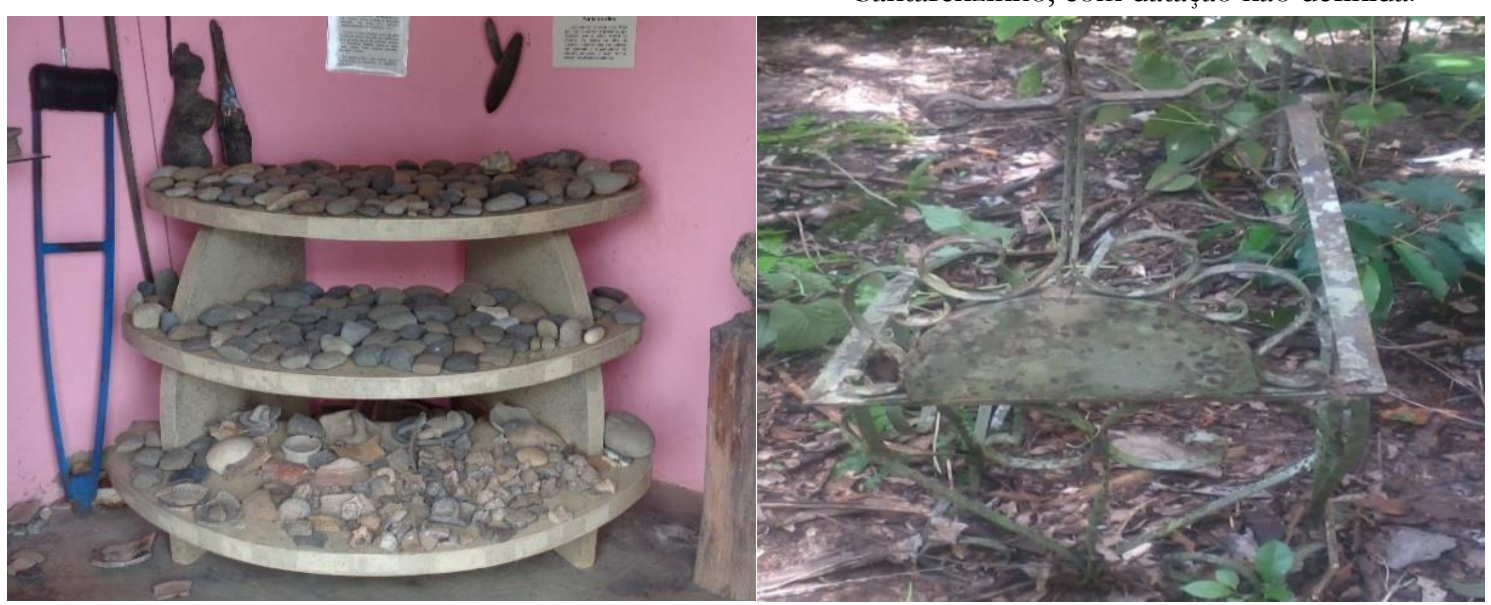

Autora: Débora Aquino Nunes, 2015.

Sendo umas das mais antigas comunidades nessa região, Santarenzinho está registrado em livros de missionários no século XVIII (SANTARÉM, 1973). Essa comunidade é o principal espaço que já está sendo impactado pelo projeto de implementação das ETCs no território. Isso porque, apesar desses empreendimentos ainda não estarem em operação, as três ETCs que estão previstas para se instalarem em Rurópolis estão localizadas em tal comunidade, levando ao aumento da especulação fundiária e conflitos agrários.

Em todas as comunidades, identificamos a importância do rio para o transporte de pessoas e a movimentação constante de diversos tipos de embarcações, principalmente canoas, rabetas e "popopo" nos furos, lagos e no rio Tapajós. Existe também uma linha de transporte de passageiros, denominada Lago do Roque/Itaituba, que sai toda manhã de terça e sexta do Lago do Roque para Itaituba, com paradas nas comunidades de Nazaré, do Livramento e de Santarenzinho. Essa linha é formada por um barco "popopo" que possui a capacidade de transportar 30 (trinta) pessoas sentadas e 25 (vinte e cinco) na rede.

Ademais, existe um porto de embarque de gado em Santarenzinho, que conta com balsas para o transporte de animais. Destaca-se que a movimentação de balsas foi identificada apenas em Santarenzinho, pois ela é a única comunidade localizada às margens do Rio Tapajós. Todas as outras comunidades são margeadas por lagos ou pequenos rios que desaguam no Tapajós, denominados na região de "furos".

As maiores e mais intensamente frequentadas áreas comunitárias são a de Santarenzinho (Fig. 06) e Nazaré (Fig. 07). As Áreas Comunitárias são espaços considerados pelos moradores como essencial para a permanência da história e do modo de vida da comunidade. Todas as edificações encontradas foram construídas pelos comunitários em parceria com o Estado, principalmente com o governo federal, ou com a 
| Os grandes projetos e os espaços de resistência na Amazônia: as comunidades em áreas de influência direta das estações portuárias em Rurópolis-PA|

| Débora Aquino Nunes | Gesiane Oliveira Trindade | David Durval Jesus Vieira |

Igreja. Com isso, esse espaço aparece também como de extrema relevância para a cultura e para a manutenção das sociabilidades da comunidade.

Figura 06 - Área Comunitária de Santarenzinho: sede do clube de recreação e pequena Igreja.

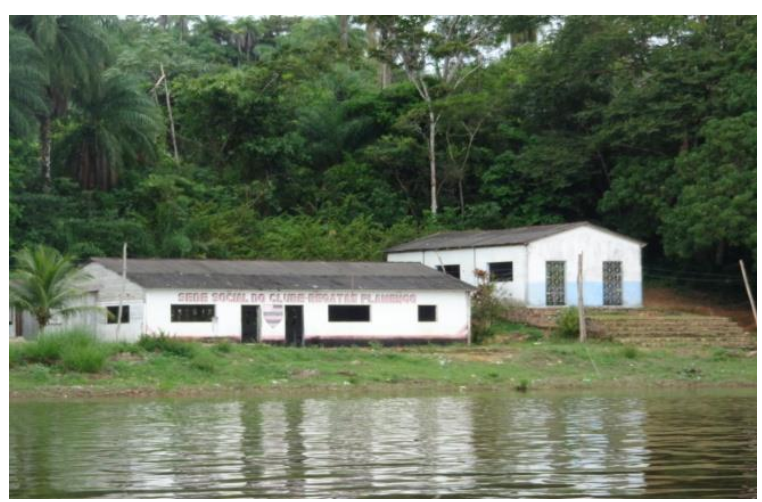

Figura 07 - Campo de Futebol da Área Comunitária de Nazaré.

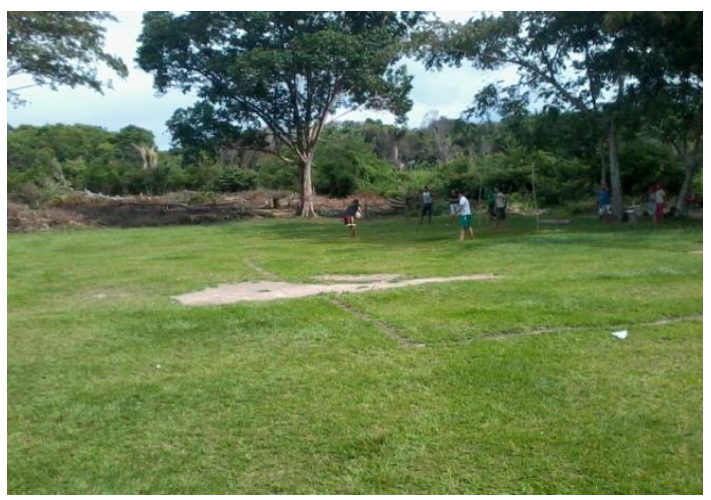

Autora: Débora Aquino Nunes, 2015.

Destacamos que, atualmente, Santarenzinho possui um time de futebol amador. Segundo o representante comunitário e o representante do clube, todos os prêmios conquistados por eles são divididos. Do valor total arrecadado, 50\% vai para obras e necessidades da comunidade e os outros 50\% fica para custear as despesas do clube. Em Santarenzinho também identificamos a realização de atividade turística, principalmente organizada pela Pousada Tapajós.

Ademais, em todas as comunidades existem tabernas de revenda de produtos industrializados, principalmente alimentícios e/ou gás de cozinha. É importante frisar que as famílias que possuem atividades ligadas ao comércio também se ocupam com a pesca e/ou com as plantações, roças e criação de animais.

Em relação à quantidade de famílias que, atualmente, habita essas comunidades identificamos que é de 72, variando de 8 a 33 famílias por comunidade. As duas maiores comunidades são a de Nazaré e Lago do Roque (Tabela 01).

Tabela 01 - Total de famílias nas comunidades analisadas

\begin{tabular}{l|c}
\hline \multicolumn{1}{c|}{ Comunidade } & Número de Famílias \\
\hline Santarenzinho & 15 \\
\hline Livramento & 8 \\
\hline Nazaré & 33 \\
\hline Lago do Roque & 16 \\
\hline Total & $\mathbf{7 2}$ \\
\hline
\end{tabular}

Fonte: Trabalho de campo, 2015. Elaboração: Débora Aquino Nunes. 
| Os grandes projetos e os espaços de resistência na Amazônia: as comunidades em áreas de influência direta das estações portuárias em Rurópolis-PA|

|Débora Aquino Nunes | Gesiane Oliveira Trindade | David Durval Jesus Vieira |

É importante destacar que, segundo informações dos comunitários, Santarenzinho, onde os projetos da ETC Rurópolis, ETC Tapajós e ETC Santarenzinho serão implantados, vem sofrendo impactos em termos de quantidade de famílias. Com a notícia de instalação desses empreendimentos, o preço da terra sofreu um aumento considerável. Por exemplo, foi relatado, por mais de um entrevistado, que a partir de 2012, quando a notícia já se espalhava na região, um lote de 10 hectares era vendido no entorno de $\mathrm{R} \$$ 350.000,00. Em 2015, o preço da terra dos mesmos 10 hectares poderia girar em torno de $\mathrm{R} \$ 1.000 .000,00$, ou seja, um aumento de mais de $175 \%$ por hectare.

Com isso, antes da notícia de implantação desses estabelecimentos, a comunidade de Santarenzinho era composta de 30 famílias, ou seja, 50\% das famílias que habitavam esse local, após a divulgação da implantação desses portos, venderam suas terras e se mudaram. O principal destino apontado foram as outras comunidades da região com aspectos mais urbanos, principalmente a do Km 30 e Miritituba - no município de Itaituba, bem como a sede de tal município vizinho.

Segundo informação dos moradores, a maioria das famílias que se mudou acabou gastando o dinheiro e, atualmente, encontra-se em uma condição preocupante, visto que poucos possuem emprego formal ou terra para trabalhar e instrumentos e condições para pescar. Por isso, muitas famílias das comunidades pesquisadas ainda resistem nas suas terras.

Assim, analisamos a produção do espaço das comunidades que estão localizadas nas áreas que serão diretamente afetadas pela operação das ETCs no município de Rurópolis, com seus elementos significantes e seus significados para as diversas práticas sociais e vivências ligadas às múltiplas e intensas relações com a terra e a água na zona rural.

A produção do espaço dessas comunidades se desenvolve de forma múltipla e multifacetada e muitas vezes nos remete às relações de parentesco e amizade, de resistências e virtualidades amazônicas. Apesar de reproduzirem certos padrões de sociabilidades e de práticas socioespaciais percebidas através de um contexto hegemônico, no qual todas as comunidades estão inseridas de maneira diferencial e desigual, tem sempre algo que foge, que é novo e que não sucumbe às ordens impostas.

O viver também (re)existe. Porém, as novas possibilidades construídas entre o viver e o perceber o espaço são pouco consideradas pelo Estado e suas políticas públicas para região. O conceber o espaço em Rurópolis e no oeste paraense está muito mais ligado à ordem hegemônica e ao espaço percebido e construído pelo capital, do que necessariamente às necessidades e apontamentos da maneira de se ver e viver a região por sua população. 
| Os grandes projetos e os espaços de resistência na Amazônia: as comunidades em áreas de influência direta das estações portuárias em Rurópolis-PA|

| Débora Aquino Nunes | Gesiane Oliveira Trindade | David Durval Jesus Vieira |

Ademais, destaca-se que essas comunidades estão inseridas dentro de um processo de inclusão precária da modernidade. Nesse sentido, muitas vezes as contradições da ordem hegemônica atacam as condições de vida dos mais diversos grupos sociais, levando os mesmos a produzir estratégias diversas de sobrevivência (MARTINS, 2008). Isto é, mesmo em meio ao discurso desenvolvimentista e economicista praticado, principalmente, pelas empresas, pelo Estado, pela mídia e por outros grupos hegemônicos, as comunidades pesquisadas resistem numa luta contínua entre apropriação do espaço e ataques do capital nacional e internacional.

As famílias continuam habitando as comunidades que já estão sendo impactadas desde a fase de planejamento das ETC's. Lá, os grandes projetos já não são mais vistos com bons olhos, sendo comuns as preocupações com o aumento da violência dos mais diversos tipos, com a especulação fundiária, com as modificações do uso do rio, entre outras problemáticas que grandes projetos na Amazônia historicamente vêm trazendo, segundo os relatos das próprias pessoas das comunidades.

\section{CONSIDERAÇÕES FINAIS}

O estudo aqui desenvolvido mostrou como está sendo produzido o espaço das comunidades Santarenzinho, Livramento, Nazaré e Lago do Roque, em área diretamente afetada (ADA) pelos projetos de Estações de Transbordo de Cargas (ETCs) Rurópolis, Tapajós e Santarenzinho, localizados no município de Rurópolis, oeste paraense.

Destacamos que a região amazônica do oeste paraense foi fortemente afetada pela abertura da fronteira econômica regional, principalmente, a partir da década de 1960. Esse processo deu um novo sentido e valor ao rio, à terra e floresta, imprimindo novas dinâmicas de uso ao espaço. Foi através da concepção da Amazônia enquanto nova fronteira do capital que o município de Rurópolis teve origem, com o programa de urbanismo rural, implantado pelo INCRA na região.

Destaca-se que o papel do Estado na produção do espaço amazônico continua sendo central para analisar suas mudanças e permanências. As políticas de abertura da fronteira ainda não cessaram. Atualmente, no oeste paraense são vários os grandes projetos com incentivo público voltados à mineração e à infraestrutura (construção de portos e rodovias), por exemplo. Dentre estes, destacamos nesse trabalho as ETCs Rurópolis, Tapajós e Santarenzinho, que fazem parte de uma política maior para construção de infraestruturas mais adequadas ao capital ligado ao agronegócio e à monocultura de grãos. 
|Os grandes projetos e os espaços de resistência na Amazônia: as comunidades em áreas de influência direta das estações portuárias em Rurópolis-PA|

| Débora Aquino Nunes | Gesiane Oliveira Trindade | David Durval Jesus Vieira |

Assim, visa-se diminuir o tempo de transporte das mercadorias dentro do território brasileiro, possibilitando seu maior e menos custoso fluxo. Diminui-se, então, o tempo de giro do capital, base para a sobrevivência do modo de produção.

Identificamos que mesmo se verificando o avanço da lógica da troca e das relações mercadófilas impostas ao espaço das comunidades pesquisadas, a vida ligada ao rio, à floresta e à terra permanece e se (re)produz. Sem deixar de existir e resistir, ela sobrevive e passa a coexistir com a recente tendência hegemônica de apropriação/dominação econômica na Amazônia.

Assim, nas comunidades que estão na AID das ETCs - Santarenzinho, Livramento, Nazaré e Lago do Roque, coexistem novas tendências de dominação da orla fluvial, baseadas principalmente no seu uso econômico, com (sobre)vivências e resistências que, muitas vezes, confrontam-se com esse processo, dia após dia. Isto é, juntamente com os processos modernizantes de parte da orla do município de Rurópolis, que invade a vida cotidiana de todos na região, (re)existe uma permanência de práticas socioespaciais marcadamente ribeirinhas e agroextrativistas, que muitas vezes fogem à lógica hegemônica. Porém, em virtude dos interesses econômicos, do desrespeito à identidade e cultura desses povos, pelo poder público e privado, e da falta de proteção aos seus conhecimentos e territórios, a sobrevivência dessas comunidades passou a ser ameaçada.

Assim, é dentro da simultaneidade entre o vivido, o percebido e concebido é que atualmente podemos analisar a produção do espaço das comunidades diretamente afetas pelo projeto de ETCs no município de Rurópolis. Frisamos que é necessário, então, atentar para além do que se repete e faz parte de maneira desigual e diferente da lógica hegemônica. A atenção voltada para as demandas produzidas pelas vivências na região dá visibilidade a sujeitos pouco visíveis em face das novas estratégias de desenvolvimento urbano e regional. O sentido do valor de uso atribuído às práticas tidas muitas vezes como de menor importância pode igualmente contribuir para a transformação social. Com efeito, destaca-se que é no inconformismo do homem comum em relação à degradação de sua vida cotidiana enquanto obra que mora a semente capaz de transformar o rumo do amanhã (MARTINS, 2011).

\section{REFERÊNCIAS}

AMBIENTARE. Ambientare Consultoria Ambiental. Relatório de Impacto Ambiental das ETC's Santarenzinho. Brasília: AMBIENTARE, 2014a. 92 p.

AMBIENTARE. Ambientare Consultoria Ambiental. Relatório de Impacto Ambiental das ETC's Rurópolis. Brasília: AMBIENTARE, 2014b. 94 p. 
|Os grandes projetos e os espaços de resistência na Amazônia: as comunidades em áreas de influência direta das estações portuárias em Rurópolis-PA|

| Débora Aquino Nunes | Gesiane Oliveira Trindade | David Durval Jesus Vieira |

AMBIENTARE. Ambientare Consultoria Ambiental. Relatório de Impacto Ambiental das ETC's Tapajós. Brasília: AMBIENTARE, 2014c. 109 p.

BECKER, B. K. Amazônia. São Paulo: Ática, 1990. 112 p.

CONAMA/IBAMA. Conselho Nacional do Meio Ambiente/Instituto Brasileiro de Meio Ambiente e Recursos Naturais Renováveis. Resolução CONAMA n ${ }^{\circ} 1$, de 23 de janeiro de 1986. Diário Oficial [da] República Federativa do Brasil, Poder Executivo, Brasília, DF, Seção 1, p. 2548-2549, 17 fev. 1986.

CARDOSO, A. C. D.; LIMA, J. J. F. A influência do governo federal sobre cidades na Amazônia: os casos de Marabá e Medicilândia. Novos cadernos NAEA, Belém, v. 12, n. 1, p. 161-192, jun. 2009. Disponível em: $<\underline{\text { http://repositorio.ufpa.br/jspui/bitstream/2011/2124/1/Artigo InfluenciaGovernoFed }}$ eral.pdf>. Acesso em: 23 ago. 2016.

CASTRO, E. M. R. Tradição e modernidade: a propósito de processos de trabalho na Amazônia. Novos Cadernos NAEA, Belém, v. 2, n. 1, p. 31-50, dez. 1999. Disponível em: $<$ http://repositorio.ufpa.br/jspui/bitstream/2011/5630/1/Artigo TradicaoModernidade Proposito.pdf>. Acesso em: 23 ago. 2016.

Urbanização, pluralidade e singularidades das cidades amazônicas. In: CASTRO, E. M. R. (Org.). Cidades na floresta. São Paulo: Annablume, 2008. 5-16 p.

CORRÊA, R. L. A periodização da rede urbana da Amazônia. Revista Brasileira de Geografia, Rio de Janeiro, v. 49, n. 3, p. 39-68, jul./set. 1987. Disponível em: $<\underline{\text { https://biblioteca.ibge.gov.br/visualizacao/periodicos/115/rbg } 1987 \text { v49 n3.pdf>. }}$

Acesso em: 23 ago. 2016.

DUTRA, M. O Pará dividido: discurso e construção do Estado do Tapajós. 1997. Dissertação (Mestrado em Planejamento do Desenvolvimento) - Núcleo de Altos Estudos Amazônicos, Universidade Federal do Pará, Belém, 1997.

EMMI, M. F. A oligarquia do Tocantins e o domínio dos castanhais. 2. ed. Belém: UFPA/NAEA, 1999. 196 p.

ENGEL, V. L. Introdução aos Sistemas Agroflorestais. Botucatu: FEPAF, 1999. 70 p.

FRASER, M. T. D.; GODIM, S. M. G. Da fala do outro ao texto negociado: discussões sobre a entrevista na pesquisa qualitativa. Paidéa, Santos, v. 14, n. 28, p. 139-152, 2004. Disponível em: < $\underline{\text { https://www.scielo.br/pdf/paideia/v14n28/04.pdf> }}$. Acesso em: 23 ago. 2016.

IBAMA. Instituto Brasileiro do Meio Ambiente e dos Recursos Naturais Renováveis. Resolução CONAMA nº 001, de 23 de janeiro de 1986. Brasília: IBAMA, 1986.

LEFEBVRE, H. La productión de l'espace. Paris: Anthropos, 1974. 487p.

O direito à cidade. 5. ed. São Paulo: Centauro, 2008a. 146 p.

A revolução urbana. Belo Horizonte: UFMG, 2008b. 212 p. 
|Os grandes projetos e os espaços de resistência na Amazônia: as comunidades em áreas de influência direta das estações portuárias em Rurópolis-PA|

|Débora Aquino Nunes | Gesiane Oliveira Trindade | David Durval Jesus Vieira |

LIMA, M. M. A ribeira e a orla: espacialidades e territorialidades urbanas ribeirinhas em uma cidade amazônica em transformação. 2013. Dissertação (Mestrado em Geografia) Instituto de Filosofia e Ciências Humanas, Universidade Federal do Pará, Belém, 2013.

MACHADO, L. O. Urbanização e mercado de trabalho na Amazônia brasileira. Cadernos IPPUR, Rio de Janeiro, v. 13, n.1, p. 109-138, jan./jul. 1999.

MAGNANI, J. G. C. De perto e de dentro: notas para uma etnografia urbana. Revista Brasileira de Ciências Sociais, São Paulo, v. 17, n. 49, p. 11-29, jun. 2002. Disponível em: <https://www.scielo.br/pdf/rbcsoc/v17n49/a02v1749.pdf>. Acesso em: 23 ago. 2016.

MARTINS, J. S. A sociabilidade do homem simples: cotidiano e história da modernidade anômala. 3. ed. São Paulo: Contexto, 2011. 210 p. 2009. 188 p.

Fronteira: a degradação do outro nos confins do humano. São Paulo: Hucitec,

A sociedade vista do abismo: novos estudos sobre exclusão, pobreza e classes sociais. 3. ed. Rio de Janeiro: Vozes, 2008. 232 p.

NUNES, D. A.; TRINDADE JR., S. C. (Sobre)vivências ribeirinhas na orla fluvial de Marabá-Pará: agentes, processo e espacialidades urbanas. Novos Cadernos NAEA, v. 15, n. 1, p. 209-238, jun. 2012. Disponível em: $<$ https://periodicos.ufpa.br/index.php/ncn/article/view/580/1426>. Acesso em: 23 ago. 2016.

OLIVEIRA, J. A. Amazônia: monopólio, expropriação e conflitos. São Paulo: Editora Papirus, 1987. 133 p.

OLIVEIRA, J. A. Cidades na selva. Manaus: Editora Valer, 2000. 224 p.

SAMAIN, E. "Ver" e "dizer" na tradição etnográfica: Bronislaw Malinowski e a fotografia. Horizontes Antropológicos, Porto Alegre, v. 1, n. 2, p. 23-60, jul./set. 1995. Disponível em: < http://carmenguarini.files.wordpress.com/2007/11/ver e dizer.pdf>. Acesso em: 23 ago. 2016.

SANTARÉM. Secretaria Municipal de Planejamento. Anuário de Prelazia de Santarém, Santarém, n. 10, 1973.

SANTOS, M. A natureza do espaço: técnica e tempo, razão e emoção. 4. ed. São Paulo: Hucitec, 2008. 392 p.

O espaço cidadão. 7. ed. São: Edusp, 2007. 176 p.

SEMAS. Secretaria de Meio Ambiente e Sustentabilidade do Pará. Aprovada licença prévia para estação de transbordo de carga em Rurópolis. Belém: SEMAS, 2017. Disponível em: <https://www.semas.pa.gov.br/2017/04/18/aprovada-licenca-previapara-estacao-de-transbordo-de-carga-em-ruropolis/>. Acesso em: 05 fev. 2021. 
|Os grandes projetos e os espaços de resistência na Amazônia: as comunidades em áreas de influência direta das estações portuárias em Rurópolis-PA|

|Débora Aquino Nunes | Gesiane Oliveira Trindade | David Durval Jesus Vieira |

SERIQUE, W. Governo Dialoga com empresas portuárias construção de estrada em Santarenzinho. Agencia Pará, 2019. Disponível em: < https://agenciapara.com.br/noticia/14298/>. Acesso em: 05 fev. 2021.

TRINDADE JR., S. C.; TAVARES, M. G. C. Cidades ribeirinhas na Amazônia: uma apresentação do tema. In: (Org.). Cidades ribeirinhas na Amazônia: mudanças e permanências. Belém: EDUFPA, 2008.

VENTURIERI, A. et al. Zoneamento ecológico-econômico da área de influência da rodovia BR-163. Belém do Pará: Embrapa, 2006.

VELHO, O. G. Frentes de expansão e estrutura agrária: estudo do processo de penetração numa área da Tranzamazônica. Rio de Janeiro: Zahar, 1972. 90 p.

\section{Como citar:}

\section{ABNT}

NUNES, D. A.; TRINDADE, G. O.; VIEIRA, D. D. J. Os grandes projetos e os espaços de resistência na Amazônia: as comunidades em áreas de influência direta das estações portuárias em Rurópolis-PA. InterEspaço: Revista de Geografia e Interdisciplinaridade, v. 7, e202107, 2021. Disponível em: <http://dx.doi.org/10.18764/2446-6549.e202107>. Acesso em: 29 mar. 2021.

\section{APA}

Nunes, D. A., Trindade, G. O., \& Vieira, D. D. J. Os grandes projetos e os espaços de resistência na Amazônia: as comunidades em áreas de influência direta das estações portuárias em Rurópolis-PA. InterEspaço: Revista de Geografia e Interdisciplinaridade, v. 7, e202107. Recuperado em 29 março, 2021, de http://dx.doi.org/10.18764/24466549.e202107

\section{@creative}

This is an open access article under the CC BY Creative Commons 4.0 license.

Copyright (C) 2021, Universidade Federal do Maranhão.

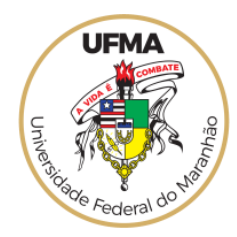

